\title{
NUTRIENTES EM CULTIVARES DE BRACHIARIA BRIZANTHA E ESTILOSANTES EM CULTIVOSOLTEIROE CONSORCIADO
}

\author{
NUTRIENTS OF BRACHIARIA BRIZANTHA AND CAMPO GRANDE STYLO \\ IN MONOCROPPING AND INTERCROPPING SYSTEMS
}

\author{
Moreira, J.F.M. ${ }^{1}$; Costa, K.A.P. ${ }^{2 *}$; Severiano, E.C. ${ }^{2}$; Simon, G.A. ${ }^{1}$; Cruvinel, W.S. ${ }^{2}$ \\ e Bento, J.C. ${ }^{1}$
}

\begin{abstract}
'Programa de Pós-Graduação em Produção Vegetal. Universidade de Rio Verde. Rio Verde-GO. Brasil. 2Programa de Pós-Graduação em Zootecnia e Ciências Agrárias. Instituto Federal Goiano. Campus Rio Verde. Rio Verde-GO. Brasil. *katiazoo@hotmail.com
\end{abstract}

\section{PaLAVRAS CHAVE ADICIONAIS \\ Brachiaria brizantha. Estação do ano.}

\section{RESUMO}

Objetivou-se avaliar a concentração de nutrientes de cultivares de Brachiaria brizantha e estilosantes 'Campo Grande' em cultivo solteiro e consorciado sob diferentes métodos de plantio, por um período de dois anos. O delineamento experimental utilizado foi de blocos completos ao acaso, com medidas repetidas no tempo, com quatro repetições, cujos tratamentos foram constituídos dos seguintes sistemas: estilosantes 'Campo Grande', capim 'Xaraés' e capim 'Marandu' solteiros ou consorciados com estilosantes, em linha ou à lanço. As avaliações foram realizadas durante dois anos por estações (outono, inverno, primavera e verão) nas mesmas parcelas. Os resultados demonstraram que a consorciação entre gramínea e leguminosa influencia no estado nutricional das forrageiras, por trazer melhoria na concentração dos nutrientes. No geral, o método de plantio em linha proporcionou melhores concentrações de nutrientes.

\section{SUMMARY}

This study evaluated the nutrient concentration of cultivars Brachiaria brizantha and estilosantes 'Campo Grande' in cropping and intercropping systems under different planting methods, for a period of two years. The experimental design was a complete randomized block, with measurements repeated over time, with four replications which treatments consisted of the following systems:

\author{
AdDitionAL KEYWORDS \\ Brachiaria brizantha. Season.
}

estilosantes 'Campo Grande'; 'Xaraés' grass; 'Marandu' grass in monocropping or intercropped with estilosantes 'Campo Grande' in rows or at broadcast. The evaluations were conducted for two years in fall, winter, spring and summer on the same plots. The results showed that intercropping grass and legume influences the nutritional status of forage improving nutrient concentration. In general, the rows planting provided better nutrient concentrations.

\section{INTRODUÇÃO}

O consórcio de gramíneas e leguminosas traz benefícios diretos para sistemas de produção animal, pelo elevado valor nutritivo que as leguminosas normalmente apresentam e ou indiretos, como a reposição de nitrogênio, por meio da fixação biológica, tornando esse nutriente disponível para as gramíneas (Souza et al., 2002). Segundo Miranda et al. (1999), pastagens de gramíneas, leguminosas puras ou consorciadas, bem estabelecidas e com manutenção das exigências nutricionais, podem-se beneficiar de microrganismos do solo, bem como da associação simbiótica com fungos micorrízicos, que aumentam a capacidade de absorção de nutrientes e da fixação bio- 
lógica do nitrogênio (FBN), principalmente pelas leguminosas, o que pode resultar em aumentos na qualidade e na quantidade de forragem.

Entre as leguminosas forrageiras tropicais destaca-se o estilosantes 'Campo Grande', que foi originado a partir de uma mistura varietal do Stylosanthes capitata e $S$. macrocephala, na proporção de 80 e $20 \%$ respectivamente. Esta variedade vem se destacando por apresentar boa adaptação a solos arenosos e com baixa fertilidade, resistência à antracnose, grande produção de sementes com boa capacidadede ressemeadura natural em campo, além de boa palatabilidade e digestibilidade, tendo teor de proteína de 15 a $24 \%$ da matéria seca. Apresenta fixação de nitrogênio atmosférico no solo, podendo fixar até $180 \mathrm{~kg}$ de nitrogênio ha- ano $^{-1}$ (Moura et al., 2011).

Conhecer as exigências nutricionais das plantas forrageiras é fator primordial para o manejo, porque interferem na produção e na qualidade da pastagem. Nesse sentido, objetivou-se avaliar a concentração de nutrientes de cultivares de Brachiaria brizantha 'Marandu' e 'Xaraés' e estilosantes 'Campo Grande' (Stylosanthes ssp) em cultivo solteiro e consorciado sob diferentes métodos de plantio, por um período de dois anos.

\section{MATERIALE MÉTODOS}

O experimento foi conduzido na Universidade de Rio Verde-GO, localizada na fazenda Fontes do Saber. A área total do experimento foi de aproximadamente $500 \mathrm{~m}^{2}$ sendo cada parcela de $16 \mathrm{~m}^{2}$. O solo foi classificado como Latossolo Vermelho distroférrico, cujas características, na camada de $0-20 \mathrm{~cm}$ de profundidade, estão apresentados na tabela I e os dados de temperatura e precipitação pluvial na figura 1.

O delineamento experimental utilizado foi de blocos completos ao acaso, com medidas repetidas no tempo e quatro repetições. Os tratamentos foram constituídos dos seguintes sistemas forrageiros: estilosantes 'Campo Grande', capim 'Xaraés' e capim 'Marandu' solteiros ou consorciados com estilosantes, em linha ou à lanço, totalizando 28 parcelas experimentais. As avaliações foram realizadas durante dois anos (outono, inverno, primavera e verão) nas mesmas parcelas. A área de cada parcela foi de $4 \times 4$ $\mathrm{m}$ e área útil de $6 \mathrm{~m}^{2}$.

O preparo da área foi realizado eliminando as plantas invasoras com aplicação de glifosato na dosagem de $1500 \mathrm{~g} \mathrm{ha}^{-1}$. Vinte dias após a dessecação foi aplicado $900 \mathrm{~kg}$ ha $^{-1}$ de calcário dolomítico $100 \%$ PRNT (poder relativo de neutralizante total)e, posteriormente, realizada uma gradagem, seguida da niveladora.

No plantio foram aplicados $100 \mathrm{~kg} \mathrm{ha}^{-1}$ de $\mathrm{P}_{2} \mathrm{O}_{5}, 60 \mathrm{~kg} \mathrm{ha}^{-1}$ de $\mathrm{K}_{2} \mathrm{O}$ e $20 \mathrm{~kg} \mathrm{ha}^{-1}$ de FTE (elementos traços fritados BR-12), utilizando como fontes: super fosfato simples, cloreto de potássio e fritas, respectivamente. No segundo ano foi realizada adubação de manutenção com $80 \mathrm{~kg} \mathrm{ha}^{-1}$ de $\mathrm{P}_{2} \mathrm{O}_{5}$ e 60 $\mathrm{kg} \mathrm{ha}^{-1}$ de $\mathrm{K}_{2} \mathrm{O}$, provenientes das fontes de superfosfato simples e cloreto de potássio, respectivamente. Para os tratamentos com gramíneas solteiras foram aplicados $90 \mathrm{~kg}$ $\mathrm{ha}^{-1}$ de nitrogênio por ano, parcelado em três aplicações, utilizando como fonte o sulfato de amônio.

Para o plantio das forrageiras foram aplicados 5 e $9 \mathrm{~kg} \mathrm{ha}^{-1}$ de sementes puras viáveis do estilosantes 'Campo Grande' e capins 'Marandu' e 'Xaraés', respectivamente. O plantio do consórcio em linha foi constituído de 8 linhas (4 da gramínea e 4 da leguminosa) de 4,0 m cada, sendo, com espaçamento entre linhas de $50 \mathrm{~cm}$. Após germinação das sementes, foi realizado o desbate das plantas, nos dois sistemas consorciados (linha e lanço) permanecendo, com isso, o mesmo número de plantas de gramínea e leguminosa.

As avaliações dos sistemas forrageiros foram realizadas no período das águas e da seca, coletando duas amostras de $1 \mathrm{~m}^{2}$ por parcela, de forma que foram amostradas gramíneas e leguminosas. Para o método de 
Tabela I. Características químicas e físicas do solo dos sistemas forrageiros em 2008 e 2009. (Physical and chemical characteristics of soil from forage systems in 2008 and 2009).

\begin{tabular}{lcclcc}
\hline Características & 2008 & 2009 & Características & 2008 & 2009 \\
\hline $\mathrm{pH}\left(\mathrm{CaCl}_{2}\right)$ & 4,4 & 5,1 & $\mathrm{~V}(\%)$ & 32,0 & 46,0 \\
$\mathrm{Al}^{3+}\left(\mathrm{cmol}_{\mathrm{c}} \mathrm{dm}^{-3}\right)$ & 0,45 & 0,1 & $\mathrm{Cu}(\mathrm{mg} \mathrm{dm}-3)$ & 3,4 & 2,7 \\
$\mathrm{H}+\mathrm{Al}\left(\mathrm{cmol}_{\mathrm{c}} \mathrm{dm}^{-3}\right)$ & 4,8 & 4,1 & $\mathrm{Zn}\left(\mathrm{mg} \mathrm{dm}^{-3}\right)$ & 1,5 & 1,9 \\
$\mathrm{Ca}^{2+}\left(\mathrm{cmol}_{\mathrm{c}} \mathrm{dm}^{-3}\right)$ & 1,36 & 2,19 & $\mathrm{Fe}\left(\mathrm{mg} \mathrm{dm}^{-3}\right)$ & 43,0 & 30,0 \\
$\mathrm{Mg}^{2+}\left(\mathrm{cmol}_{\mathrm{c}} \mathrm{dm}^{-3}\right)$ & 0,73 & 0,98 & $\mathrm{Mn}\left(\mathrm{mg} \mathrm{dm}^{-3}\right)$ & 38,4 & 41,0 \\
$\mathrm{~K}^{+}\left(\mathrm{cmol}_{\mathrm{c}} \mathrm{dm}^{-3}\right)$ & 0,17 & 0,33 & $\mathrm{M} . \mathrm{O} \cdot\left(\mathrm{g} \mathrm{dm}^{-3}\right)$ & 18,6 & 21,7 \\
$\mathrm{CTC}\left(\mathrm{cmol}_{\mathrm{c}} \mathrm{dm}^{-3}\right)$ & 7,05 & 7,6 & Argila $\left(\mathrm{g} \mathrm{kg}^{-1}\right)$ & 600 & 600 \\
$\left.\mathrm{P}_{-} \mathrm{Mehlich-1}^{-1} \mathrm{mg} \mathrm{dm}^{-3}\right)$ & 2,07 & 4,3 & Silte $\left(\mathrm{g} \mathrm{kg}^{-1}\right)$ & 350 & 350 \\
$\mathrm{SO}_{4}^{-2}\left(\mathrm{mg} \mathrm{dm}^{-3}\right)$ & 9,6 & 10,9 & Areia $\left(\mathrm{g} \mathrm{kg}^{-1}\right)$ & 50 & 50 \\
\hline
\end{tabular}

plantio a lanço aleatoriamente, dentro da área útil da parcela. A altura de corte foi de $20 \mathrm{~cm}$ do solo. Ao longo de dois anos, para todos os sistemas de produção foram realizados 14 cortes de avaliação, nos seguintes períodos: Outono (março de 2008/2009 e maio de 2008/2009); Inverno (julho de 2008/ 2009 e setembro de 2008/2009); Primavera (outubro de 2008/2009 e dezembro de 2008/ 2009); Verão (janeiro de 2009/2010).

O material coletado no campo foi acondicionado em sacos plásticos e enviado ao laboratório, onde foi retirada uma amostra representativa de cada parcela de, aproximadamente, $500 \mathrm{~g}$ e colocado em estufa de ventilação forçada a $55^{\circ} \mathrm{C}$, por 72 horas, para pré-secagem. Posteriormente as amostras foram moídas e armazenadas em sacos plásticos, para serem analisadas.

A análise química foi realizada na planta inteira para determinação das concentrações de $\mathrm{N}, \mathrm{P}, \mathrm{Ca}, \mathrm{Mg}$ e $\mathrm{K}$, com base na matéria seca (MS) das forrageiras. Para determinação do N, as amostras foram submetidas à digestão sulfúrica. $\mathrm{O} P$ à digestão úmida, utilizando a mistura nitroperclórica e a leitura foi realizada por colorimetria. $\mathrm{OK}$ por fotometria de chama e o Ca e $\mathrm{Mg}$ foram determinados por espectrofotometria de absorção atômica, de acordo com a metodologia descrita por Malavolta et al. (1997).

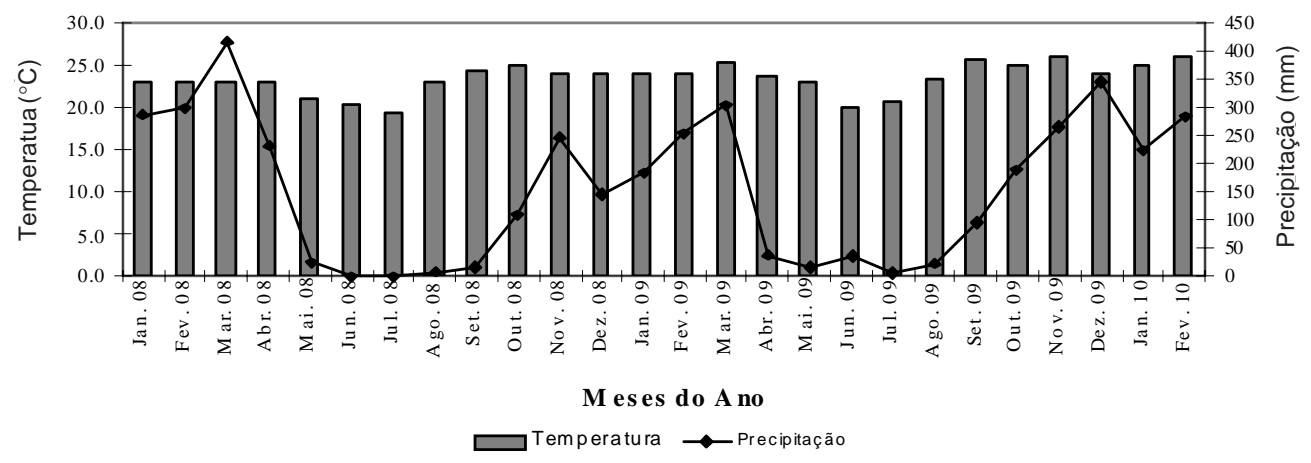

Figura 1. Temperaturas médias $\left({ }^{\circ} \mathrm{C}\right)$ e precipitações pluviais $(\mathrm{mm})$ observadas durante o período de janeiro de 2008 a fevereiro de 2010, em Rio Verde-GO. (Average temperatures $\left({ }^{\circ} \mathrm{C}\right.$ ) and precipitation (mm) observed during the period of January 2008 to February 2010 in Rio Verde-GO). 
Os dados foram submetidos à análise de variância e as médias comparadas pelo teste de Tukey, com nível de significância de $5 \%$ de probabilidade. Para os anos de avaliação, as análises foram realizadas pelo modelo de parcela subdividida no tempo, conforme adequação de modelos lineares de Gauss Markov, utilizando o software SISVAR (Ferreira, 2000).

\section{RESULTADOSEDISCUSSÃO}

As concentrações de nitrogênio, fósforo, cálcio, magnésio e potássio foram influenciadas $(\mathrm{p}<0,05)$ pelos sistemas forrageiros, estações do ano, bem como a interação desses fatores.

Quando analisa-se os sistemas forrageiros dentro de cada estação do ano (tabela II), observa-se que, no outono, o estilosantes 'Campo Grande' solteiro obteve as maiores concentrações de nitrogênio, seguido dos consórcios com as gramíneas em linha e a lanço. No inverno, apenas as gramíneas solteiras diferenciaram dos outros sistemas, com menores concentrações. Já na primavera, todos os sistemas forrageiros foram influenciados, com maiores concentrações de nitrogênio para o estilosantes 'Campo Grande' solteiro, seguido dos capins 'Xaraés' e 'Marandu' consorciado com o estilosantes 'Campo Grande' em linha. Esse resultado pode ser decorrente da menor competição das forrageiras, quando plantadas em linha. No entanto, no verão, os sistemas consorciados apresentaram concentrações semelhantes entre as formas de plantio. Em todas as estações estudadas, houve aumento expressivo na concentração de nitrogênio nos sistemas consorciados.

Cantarutti e Boddey (1997) relataram que, parte do nitrogênio fixado pela leguminosa,

Tabela II. Concentração sazonal de N e P em plantas dos sistemas forrageiros. (Seasonal concentrations of $\mathrm{N}$ and $\mathrm{P}$ in plants of forage systems).

\begin{tabular}{|c|c|c|c|c|}
\hline Sistemas forrageiros & outono & inverno & primavera & verão \\
\hline \multicolumn{5}{|l|}{ Concentrações de nitrogênio ( $\mathrm{g} \mathrm{kg}^{-1}$ na MS) } \\
\hline Estilosantes 'Campo Grande' & $30,72^{\mathrm{Aa}}$ & $23,84^{\mathrm{Ab}}$ & $30,72^{\mathrm{Aa}}$ & $28,32^{\mathrm{Aa}}$ \\
\hline 'Xaraés' & $21,44^{\mathrm{Ca}}$ & $15,36^{\mathrm{BC}}$ & $16,32^{\mathrm{Db}}$ & $17,28^{\mathrm{cb}}$ \\
\hline 'Marandu' & $22,43^{\mathrm{Ca}}$ & $14,88^{\mathrm{BC}}$ & $17,44^{\mathrm{Db}}$ & $16,48^{\mathrm{cb}}$ \\
\hline 'Xaraés' x estilosantes 'Campo Grande' linha & $25,76^{\mathrm{Ba}}$ & $19,36^{\mathrm{AC}}$ & $26,56^{\mathrm{Ba}}$ & $22,56^{\mathrm{Bb}}$ \\
\hline 'Xaraés' x estilosantes 'Campo Grande' lanço & $25,12^{\mathrm{Ba}}$ & $18,24^{\mathrm{Ac}}$ & $22,40^{\mathrm{cb}}$ & $19,84^{\mathrm{Bb}}$ \\
\hline 'Marandu' x estilosantes 'Campo Grande' linha & $25,76^{\mathrm{Ba}}$ & $19,84^{\mathrm{Ac}}$ & $24,96^{\mathrm{Ba}}$ & $20,80^{\mathrm{Bb}}$ \\
\hline 'Marandu' x estilosantes 'Campo Grande' lanço & $25,12^{\mathrm{Ba}}$ & $18,08^{\mathrm{Ac}}$ & $21,44^{\mathrm{Cb}}$ & $19,84^{\mathrm{Bb}}$ \\
\hline CV $(\%)$ & \multicolumn{4}{|c|}{8,24} \\
\hline \multicolumn{5}{|l|}{ Concentrações de fósforo ( $\mathrm{g} \mathrm{kg}^{-1}$ na MS) } \\
\hline Estilosantes 'Campo Grande' & $5,16^{\mathrm{Aa}}$ & $2,85^{\mathrm{Ab}}$ & $6,41^{\mathrm{Aa}}$ & $5,66^{\mathrm{Aa}}$ \\
\hline 'Xaraés' & $3,03^{\mathrm{Ca}}$ & $2,13^{A b}$ & $3,34^{\mathrm{Ca}}$ & $3,19^{\mathrm{Ba}}$ \\
\hline 'Marandu' & $2,46^{\mathrm{Ca}}$ & $1,56^{\mathrm{Bb}}$ & $3,11^{\mathrm{Ca}}$ & $2,92^{\mathrm{Ba}}$ \\
\hline 'Xaraés' $x$ estilosantes 'Campo Grande' linha & $3,92^{\mathrm{Bb}}$ & $2,26^{\mathrm{AC}}$ & $5,21^{\mathrm{Aa}}$ & $3,14^{\mathrm{Bb}}$ \\
\hline 'Xaraés' x estilosantes 'Campo Grande' lanço & $3,57^{\mathrm{Bb}}$ & $2,17^{\mathrm{Ac}}$ & $4,00^{\mathrm{Ba}}$ & $2,93^{\mathrm{Bb}}$ \\
\hline 'Marandu' x estilosantes 'Campo Grande' linha & $4,65^{\mathrm{Aa}}$ & $2,39^{A b}$ & $4,16^{\mathrm{Ba}}$ & $4,03^{\mathrm{Ba}}$ \\
\hline 'Marandu' x estilosantes 'Campo Grande' lanço & $3,80^{\mathrm{Ba}}$ & $2,12^{\mathrm{Ab}}$ & $3,75^{\mathrm{Ca}}$ & $3,28^{\mathrm{Ba}}$ \\
\hline CV (\%) & \multicolumn{4}{|c|}{22,85} \\
\hline
\end{tabular}

A,B,a,bMédias seguidas por letras diferentes maiúscula na coluna (sistemas forrageiros) e minúscula na linha (estações do ano) diferem entre si pelo teste de Tukey $(p<0,05)$. 
pode ser transferida, direta ou indiretamente, para a gramínea associada por meio de produtos nitrogenados excretados pelas raízes, por fluxo de nitrogênio através de hifas de micorrizas que interconectam as raízes das duas espécies e por reabsorção do nitrogênio volatilizado ou lixiviado da folhagem da leguminosa. De acordo com Miranda et al. (1999), o estilosantes 'Campo Grande' pode fixar de 88 a $180 \mathrm{~kg} \mathrm{ha}^{-1} \mathrm{ano}^{-1}$ de nitrogênio.

Costa et al. (2008 e 2009a) verificaram aumento de 65,78 e $77 \%$ nas concentrações de nitrogênio em cultivares de Brachiaria brizantha ('MG-4', 'Marandu' e 'Xaraés') em resposta às doses de nitrogênio.

Observa-se (tabela II), que as concentrações de nitrogênio variaram em relação às estações do ano. O estilosantes 'Campo Grande', no inverno apresentou menores concentrações, devido à baixa resistência dessa leguminosa no período seco do ano, onde, ocorre produção natural de sementes e por isso, apresenta limitação para ser fornecido no período da seca.

Para os capins 'Xaraés' e 'Marandu' solteiros e consorciados com estilosantes 'Cam- po Grande' a lanço, as maiores concentrações de nitrogênio foram obtidas no outono, seguido da primavera e verão, que apresentaram concentrações semelhantes. Já para os capins 'Xaraés' e 'Marandu' consorciado com o estilosantes 'Campo Grande' em linha, as concentrações de nitrogênio do outono e primavera foram semelhantes, diferindose apenas do verão e inverno.

As concentrações de nitrogênio obtidas no estilosantes 'Campo Grande' solteiro e consorciado com as gramíneas, independente do período de avaliação, estão bem acima das necessidades dos bovinos (de 13 a $20 \mathrm{~g} \mathrm{~kg}^{-1}$ para Werner et al., 1996).

As concentrações de nitrogênio não foram influenciadas pelos tratamentos, quando se compara os anos de avaliação nos sistemas solteiros e consorciados em linha (figura 2). No entanto, para o sistema de plantio a lanço, houve decréscimo nas concentrações de nitrogênio de 31,7 e 30,4 $\%$, no segundo ano, respectivamente para o consórcio com o capim 'Xaraés' e 'Marandu', quando os mesmo foram plantados a lanço. Esse resultado é importante para o manejo de implantação de consórcio entre o
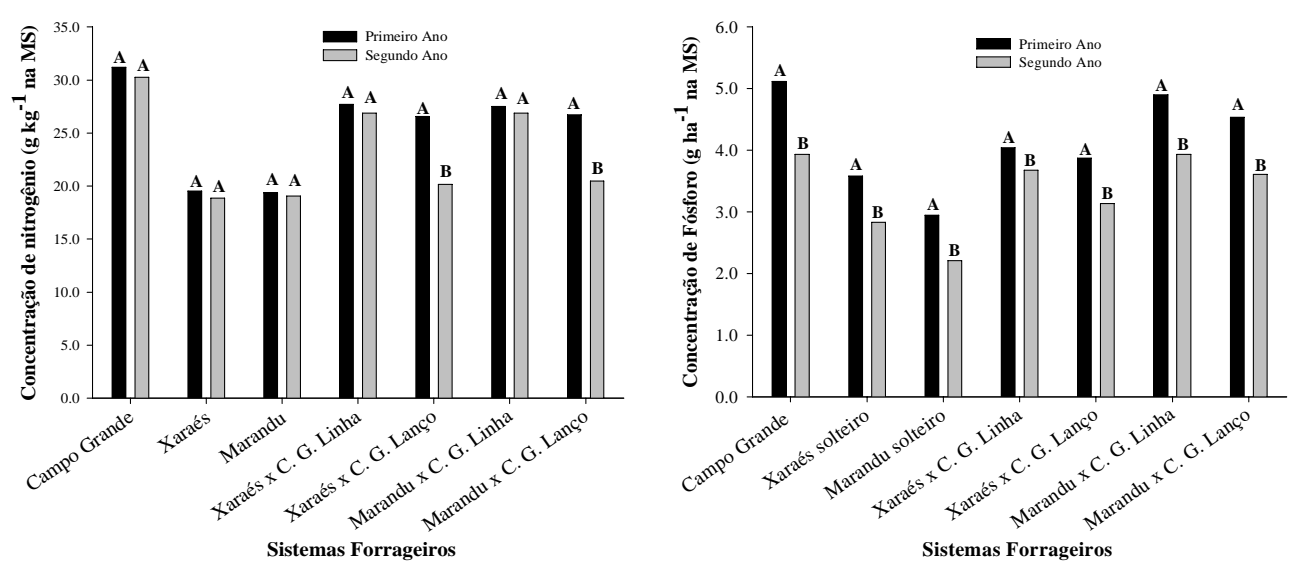

Médias seguidas por letras diferentes diferem entre si pelo teste de Tukey $(p<0,05)$.

Figura 2. Concentração de $N$ e P dos sistemas forrageiros, avaliados no primeiro e segundo ano. (Concentrations of $\mathrm{N}$ and $\mathrm{P}$ of forage systems evaluated in the first and second years). 
estilosantes 'Campo Grande' e cultivares de Brachiaria brizantha, visto que no plantio a lanço, observou-se menor persistência da leguminosa em sobreviver junto com os capins 'Xaraés' e 'Marandu', apresentando um percentual de proporção de apenas $10 \%$ no segundo ano de implantação do sistema (Moreira et al., 2013). Outros fatores que explicam a menor persistência da leguminosa junto com as gramíneas, podem ser atribuídos, em parte, ao seu efeito alelopático (Almeida et al.,1997), a maior capacidade de extração de nutrientes e o hábito de crescimento cespitoso da gramínea (Barcellos et al., 2000).

Analisando as concentrações de fósforo dos sistemas forrageiros dentro de cada estação do ano (tabela II), observa-se que, no outono, o estilosantes 'Campo Grande' solteiro e o capim 'Marandu' consorciado em linha apresentaram as maiores concentrações de P. Já no inverno, apenas o capim 'Marandu' diferenciou-se dos outros sistemas com menores concentrações de fósforo. E na primavera e verão as maiores concentrações foram obtidas no estilosantes 'Campo Grande' solteiro e consorciado com o capim 'Xaraés' em linha, seguido dos sistemas de consórcio a lanço.

Para todas as estações do ano, as menores concentrações de fósforo foram verificadas nas gramíneas solteiras (tabela II). Entretanto, quando há presença da leguminosa no sistema, aumenta a concentração de fósforo das gramíneas. Carvalho et al. (2006) avaliando a Brachiaria decumbens consorciada com Calopogonium тисиnoides, verificaram que a concentração de fósforo na matéria seca da parte aérea foi significativamente superior no sistema de consórcio $\left(4,03 \mathrm{~g} \mathrm{~kg}^{-1}\right)$, quando comparado com o sistema solteiro de $B$. decumbens fertilizada $\left(1,0 \mathrm{~g} \mathrm{~kg}^{-1}\right)$.

Quando se compara as concentrações de fósforo nas estações do ano, dentro de cada sistema forrageiro (tabela II), verificase que para o estilosantes 'Campo Grande', gramíneas solteiras e capim 'Marandu' consorciado em linha e a lanço, apenas o inverno diferiu das outras estações, que não diferiram entre si. No entanto, para o sistema consorciado do capim 'Xaraés' em linha e a lanço, as maiores concentrações foram obtidas na primavera, seguido do outono e verão.

Para todos os sistemas forrageiros, as menores concentrações de fósforo foram verificadas no inverno. Este fato ocorreu, provavelmente, devido às condições climáticas adversas, como redução da precipitação, da temperatura e da radiação solar neste período do ano (figura 1), prejudicando o crescimento das forrageiras.

Comparando as concentrações de fósforo entre os anos de avaliação (figura 3), foi constatado efeito significativo em todos os sistemas forrageiros, com as maiores concentrações ocorrendo no primeiro ano de implantação dos sistemas. Isso pode estar correlacionado com a menor produção de forragem obtida nesse ano, acumulando, assim, maiores quantidades de fósforo nos tecidos da planta e causando efeito de concentração.

Analisando a concentração de cálcio dos sistemas forrageiros dentro de cada estação (tabela III), observa-se que no outono, foram obtidas as maiores concentrações, seguido dos consórcios em linha e a lanço. No entanto, para o inverno, primavera e verão, os sistemas consorciados com as gramíneas em linha apresentaram maiores concentrações de cálcio, quando comparados com os sistemas de consórcio a lanço. Moreira et al. (2005) relataram que as leguminosas são, normalmente, mais ricas em cálcio que as gramíneas. Isto é devido às gramíneas apresentarem baixa capacidade de troca de cátions na raiz (CTC de raiz) e, os solos, principalmente os mais argilosos, adsorvem mais fortemente no seu colóide cátions com valência maior $\left(\mathrm{Al}^{+3}>\mathrm{Ca}^{+2}>\right.$ $\mathrm{K}^{+}$). Portanto, as gramíneas seriam mais eficientes na remoção de cátions monovalentes $\left(\mathrm{K}^{+}\right)$do solo, por competição por sítios de ligação, que poderiam interferir negativa- 

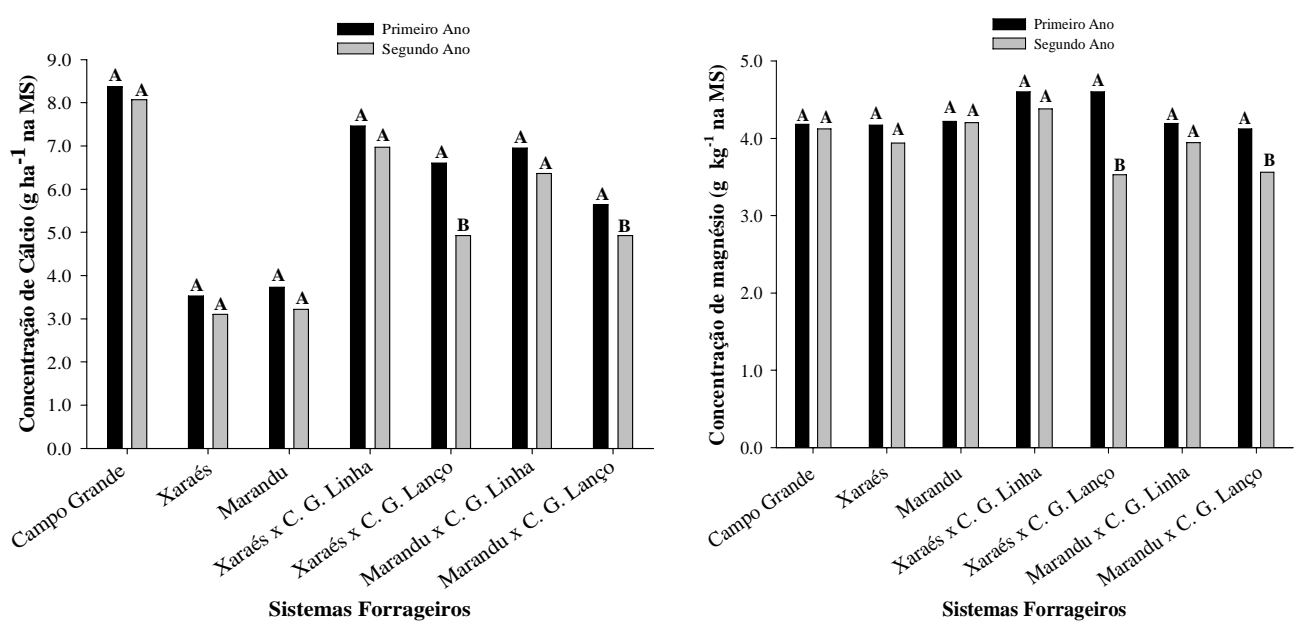

Médias seguidas por letras diferentes diferem entre si pelo teste de Tukey $(p<0,05)$.

Figura 3. Concentração de Ca e Mg dos sistemas forrageiros, avaliados no primeiro e segundo ano. (Concentrations of $\mathrm{Ca}$ and $\mathrm{Mg}$ of forage systems evaluated in the first and second years).

mente na absorção de cálcio, caracterizando o antagonismo entre os nutrientes (Marschner, 1995).

Nesse sentido, quando os consórcios com as gramíneas são realizados em linha, obtêm maiores concentrações de cálcio, devido à maior presença do estilosantes 'Campo Grande' no sistema. Barcelos et al. (2008) relataram que as leguminosas tropicais apresentam maior concentração de cálcio na forragem, quando comparada com as gramíneas, podendo ser três vezes maior $(1,2$ vs. $0,4 \%)$.

Resultados semelhantes foram obtidos por Oliveira et al. (2009), que verificaram que as concentrações de cálcio nos sistemas consorciados de $B$. decumbens e $B$. brizantha com calopogônio, foram superiores aos observados nas gramíneas solteiras. No entanto, Carvalho et al. (2006), avaliando a concentração de macronutrientes sob diferentes sistemas de cultivo (B. decumbens consorciada com calopogônio e $B$. decumbens solteira), verificaram que as concentrações de cálcio não foram influenciadas nos sistemas estudados.
Quando se compara a concentração de cálcio nas estações do ano e dentro de cada sistema de plantio, verifica-se que, para todos os sistemas forrageiros, as maiores concentrações foram obtidas na primavera e verão, diferenciando-se do outono e inverno. As menores concentrações foram verificadas no inverno para o estilosantes 'Campo Grande' solteiro e consorciado com as gramíneas a lanço, o que, provavelmente, também está relacionado aos fatores climáticos desfavoráveis nessa estação.

Quando analisa a concentração de cálcio entre os anos de avaliação (figura 4), verifica-se que, no estilosantes 'Campo Grande', gramíneas solteiras e consorciadas em linha, as concentrações de cálcio não foram influenciadas, mostrando semelhantes entre os anos avaliados. No entanto, quando o consórcio com as gramíneas foi realizado a lanço, ocorreu queda na concentração de cálcio de 33,9 e 14,5\%, para os consórcios com os capins 'Xaraés' e 'Marandu', respectivamente.

Nos dois anos avaliados, as concentrações de cálcio estão mais elevadas do 
MOREIRA, COSTA, SEVERIANO, SIMON, CRUVINELE BENTO

Tabela III. Concentração sazonal de Ca e Mg nas plantas dos sistemas forrageiros. (Seasonal concentrations of $\mathrm{Ca}$ and $\mathrm{Mg}$ in plants of forage systems).

\begin{tabular}{|c|c|c|c|c|}
\hline Sistemas forrageiros & outono & inverno & primavera & verão \\
\hline \multicolumn{5}{|l|}{ Concentrações de cálcio ( $\mathrm{g} \mathrm{kg}^{-1}$ na MS) } \\
\hline Estilosantes 'Campo Grande' & $7,61^{\mathrm{Ab}}$ & $5,99^{A c}$ & $8,23^{\mathrm{Aa}}$ & $8,06^{\mathrm{Aa}}$ \\
\hline 'Xaraés' & $2,55^{\mathrm{Cb}}$ & $2,68^{\mathrm{Db}}$ & $3,95^{\mathrm{Ca}}$ & $3,71^{\mathrm{Da}}$ \\
\hline 'Marandu' & $2,59^{\mathrm{Cb}}$ & $2,75^{\mathrm{Db}}$ & $4,19 \mathrm{Ca}$ & $4,19^{\mathrm{Da}}$ \\
\hline 'Xaraés' x estilosantes 'Campo Grande' linha & $5,77^{\mathrm{Bb}}$ & $4,20^{\mathrm{Bc}}$ & $7,22^{\mathrm{Ba}}$ & $7,64^{\mathrm{Ba}}$ \\
\hline 'Xaraés' x estilosantes 'Campo Grande' lanço & $4,80^{\mathrm{Bb}}$ & $3,56^{\mathrm{Cc}}$ & $6,09 \mathrm{Ca}$ & $6,34^{\mathrm{Ca}}$ \\
\hline 'Marandu' x estilosantes 'Campo Grande' linha & $4,99^{\mathrm{Bb}}$ & $4,18^{\mathrm{Bc}}$ & $7,19^{\mathrm{Ba}}$ & $7,75^{\mathrm{Ba}}$ \\
\hline 'Marandu' x estilosantes 'Campo Grande' lanço & $4,22^{\mathrm{Bb}}$ & $3,19^{\mathrm{Cb}}$ & $5,62^{\mathrm{Ca}}$ & $6,02^{\mathrm{Ca}}$ \\
\hline CV $(\%)$ & \multicolumn{4}{|c|}{14,35} \\
\hline \multicolumn{5}{|l|}{ Concentrações de magnésio ( $\mathrm{g} \mathrm{kg}^{-1}$ na MS) } \\
\hline Estilosantes 'Campo Grande' & $3,47^{\mathrm{Aa}}$ & $2,80^{\mathrm{Ab}}$ & $5,19^{\mathrm{Aa}}$ & $4,93^{\mathrm{Aa}}$ \\
\hline 'Xaraés' & $3,86^{\mathrm{Aa}}$ & $2,72^{\mathrm{Ab}}$ & $4,54^{\mathrm{Ba}}$ & $4,19^{\mathrm{Ba}}$ \\
\hline 'Marandu' & $4,12^{\mathrm{Aa}}$ & $2,97^{\mathrm{Ab}}$ & $4,78^{\mathrm{Ba}}$ & $4,25^{\mathrm{Ba}}$ \\
\hline 'Xaraés' x estilosantes 'Campo Grande' linha & $4,13^{\mathrm{Aa}}$ & $2,71^{\mathrm{Ab}}$ & $5,14^{\mathrm{Aa}}$ & $4,96^{\mathrm{Aa}}$ \\
\hline 'Xaraés' x estilosantes 'Campo Grande' lanço & $4,28^{\mathrm{Aa}}$ & $2,92^{\mathrm{Ab}}$ & $4,58^{\mathrm{Ba}}$ & $4,12^{\mathrm{Ba}}$ \\
\hline 'Marandu' x estilosantes 'Campo Grande' linha & $3,46^{\mathrm{Aa}}$ & $2,81^{\mathrm{Ab}}$ & $5,07^{\mathrm{Aa}}$ & $4,97^{\mathrm{Aa}}$ \\
\hline 'Marandu' x estilosantes 'Campo Grande' lanço & $3,87^{\mathrm{Aa}}$ & $2,79^{A b}$ & $4,25^{\mathrm{Ba}}$ & $4,04^{\mathrm{Ba}}$ \\
\hline CV $(\%)$ & \multicolumn{4}{|c|}{13,54} \\
\hline
\end{tabular}

A,B,a,bMédias seguidas por letras diferentes maiúscula na coluna (sistemas forrageiros) e minúscula na linha (estações do ano) diferem entre si pelo teste de Tukey $(p<0,05)$.

que as indicadas por Malavolta et al. (1986), que relataram que a faixa adequada para as forrageiras na alimentação de ruminantes está entre 1,5 e $6,0 \mathrm{~g} \mathrm{~kg}^{-1}$. Oliveira et al. (2009), avaliando fontes de cálcio no desenvolvimento de gramíneas solteiras e consorciadas, verificaram concentrações de cálcio de 2,6 e 2,7 $\mathrm{g} \mathrm{kg}^{-1}$ no consórcio do capim 'Marandu' com calopogônio, quando utilizou como fonte a calagem e gessagem, respectivamente.

As concentrações de magnésio nos sistemas forrageiros dentro de cada estação não foram influenciadas no outono e inverno, não apresentando diferenças significativas entre os diferentes sistemas. Já na primavera e verão, as maiores concentrações foi verificado no estilosantes 'Campo Grande' solteiro e consorciado com as gramíneas em linha (tabela III). Ribeiro e Pereira (2011) relatam que o magnésio, como o nitrogênio, é parte estrutural da molécula de clorofila, assim, espera-se que o aumento do nitrogênio na planta, contribuindo para a formação da clorofila, proporcione mais altas exigências de magnésio.

Comparando as concentrações de magnésio nas estações do ano e dentro de cada sistema forrageiro (tabela III), observa-se que, para todos os sistemas, apenas as concentrações no inverno diferiu das demais estações, com menores concentrações. Entretanto, mesmo nesse período, as concentrações de magnésio encontram-se acima das exigências requeridas pelos ruminantes que, segundo McDowell (1999), situam-se entre 1,6 e $1,9 \mathrm{~g} \mathrm{~kg}^{-1}$. Ribeiro e Pereira (2011) verificaram que as concentrações de magnésio do capim-tifton 85 aumentaram com o incremento do nitrogênio, com valores entre 4,0 e 5,0 $\mathrm{g} \mathrm{kg}^{-1}$. Esses valores foram semelhantes aos obtidos nesse estudo 


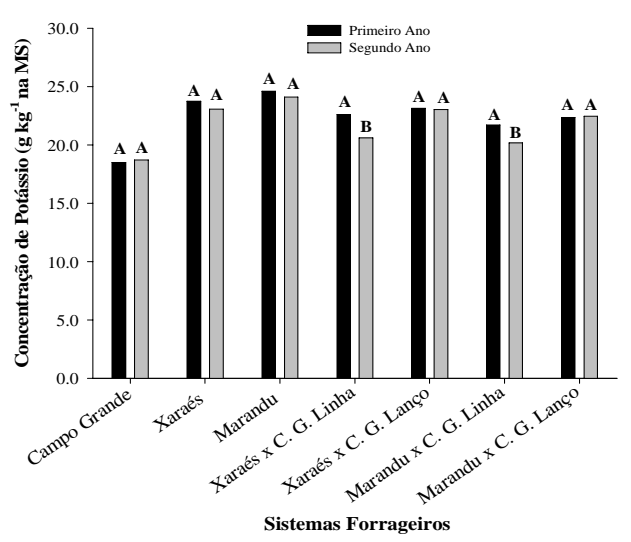

Médias seguidas por letras diferentes diferem entre si pelo teste de Tukey $(p<0,05)$.

Figura 4. Concentração de $K$ dos sistemas forrageiros, avaliados no primeiro e segundo ano. (Concentrations of $\mathrm{K}$ of forage systems evaluated in the first and second years).

para os sistemas consorciados de gramínea e leguminosa.

As concentrações de magnésio não foram influenciadas $(p>0,05)$ quando se compara os anos de avaliação para os sistemas solteiros e consorciados em linha (figura 3). No entanto, para o sistema de plantio a lanço, houve decréscimo na concentração de 30,5 e $15,7 \%$, no segundo ano, para o consórcio com o capim 'Xaraés' e 'Marandu', respectivamente. No entanto, observa-se que, no plantio do consórcio com as gramíneas em linha, a concentração de magnésio pouco variou entre os anos avaliados. Esse resultado é importante para manter o valor nutricional da forragem por vários anos.

Carvalho et al. (2006) avaliando a concentração de macronutrientes da $B$. decumbens consorciada com calopogônio e solteira, verificaram que não houve diferença significativa na concentração de magnésio, entre os sistemas, tanta na estação chuvosa, como na seca.

Com relação ao estado nutricional da planta, as concentrações de magnésio dos anos avaliados são consideradas adequadas em todos os sistemas forrageiros, ficando dentro dos níveis relatados (entre 0,5 e 2,0 $\mathrm{g} \mathrm{kg}^{-1}$ ) para pastagens de gramíneas (Malavolta, 1992).

Analisando as concentrações de potássio dos sistemas forrageiros dentro de cada estação (tabela IV), verifica-se que, no outono, as gramíneas solteiras apresentaram maiores concentrações de potássio, quando comparado com o estilosantes 'Campo Grande' solteiro e consorciado com as gramíneas

Tabela IV. Concentração de $K\left(\mathrm{~g} \mathrm{~kg}^{-1} \mathrm{na} \mathrm{MS}\right)$ nas plantas dos sistemas forrageiros.

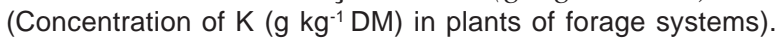

\begin{tabular}{lcccr}
\hline Sistemas forrageiros & outono & inverno & primavera & verão \\
\hline Estilosantes 'Campo Grande' & $17,87^{\mathrm{Ba}}$ & $11,63^{\mathrm{Bb}}$ & $18,40^{\mathrm{Ba}}$ & $15,57^{\mathrm{Ba}}$ \\
'Xaraés' & $21,83^{\mathrm{Aa}}$ & $16,76^{\mathrm{Ab}}$ & $23,10^{\mathrm{Aa}}$ & $20,81^{\mathrm{Aa}}$ \\
'Marandu' & $22,19^{\mathrm{Aa}}$ & $17,16^{\mathrm{Ab}}$ & $22,01^{\mathrm{Aa}}$ & $19,98^{\mathrm{Aa}}$ \\
'Xaraés' x estilosantes 'Campo Grande' linha & $18,46^{\mathrm{Ba}}$ & $16,50^{\mathrm{Ab}}$ & $19,69^{\mathrm{Ba}}$ & $17,80^{\mathrm{Ba}}$ \\
'Xaraés' x estilosantes 'Campo Grande' lanço & $19,10^{\mathrm{Ba}}$ & $16,69^{\mathrm{Ab}}$ & $21,46^{\mathrm{Aa}}$ & $20,14^{\mathrm{Aa}}$ \\
'Marandu' x estilosantes 'Campo Grande' linha & $18,48^{\mathrm{Ba}}$ & $17,82^{\mathrm{Ab}}$ & $19,07^{\mathrm{Ba}}$ & $17,85^{\mathrm{Ba}}$ \\
'Marandu' x estilosantes 'Campo Grande' lanço & $18,97^{\mathrm{Ba}}$ & $16,39^{\mathrm{Ab}}$ & $20,93^{\mathrm{Aa}}$ & $18,50^{\mathrm{Aa}}$ \\
CV (\%) & \multicolumn{3}{c}{13,37} \\
\end{tabular}

A,B,a,b Médias seguidas por letras diferentes maiúscula na coluna (sistemas forrageiros) e minúscula na linha (estações do ano) diferem entre si pelo teste de Tukey $(p<0,05)$. 
em linha e a lanço. Já no inverno, apenas o estilosantes 'Campo Grande' solteiro diferiu dos demais sistemas forrageiros, com menores concentrações. Na primavera e verão, as gramíneas solteiras e consorciados com o estilosantes 'Campo Grande' a lanço apresentaram as maiores concentrações. Esse resultado é atribuído as maiores concentrações de potássio que as gramíneas apresentaram, sendo considerado o nutriente de maior acúmulo e extração nas gramíneas tropicais (Costa et al., 2009b). Trabalhando com extração de nutrientes pela fitomassa dos cultivares de Brachiaria brizantha sob doses de nitrogênio, Costa $e t$ al. (2010), verificaram que a máxima extração de macronutrientes pelos cultivares seguiu a ordem decrescente para potássio > nitrogênio > fósforo > magnésio > enxofre.

Quando comparados os dois anos de avaliação dos diferentes sistemas forrageiros (figura 4), observa-se que, nos sistemas solteiros e consorciados com as gramíneas a lanço, as concentrações de potássio foram semelhantes entre os anos avaliados. No entanto, quando o consórcio do estilosantes 'Campo Grande' com as

\section{BIBLIOGRAFIA}

Almeida, A.R.P.; Lucchesi, A.A. e Abbado, M.R. 1997. Efeito alelopático de espécies de Brachiaria Griseb sobre algumas leguminosas forrageiras tropicais. II. Avaliações em casa de vegetação. Bol Ind Anim, 54: 45-54.

Barcellos, A.O.; Andrade, R.P.; Karia, C.T. e Vilela, L. 2000. Potencial e uso de leguminosas forrageiras dos gêneros Stylosanthes, Arachis e Leucaena. Em: Simpósio sobre Manejo da Pastagem, 17. A planta forrageira no sistema de produção. Anais... FEALQ. Piracicaba. pp. 297357.

Barcellos, A.O.; Ramos, A.K.B.; Vilela, L. e Martha Junior, G.B. 2008. Sustentabilidade da produção animal baseada em pastagens consorciadas e no emprego de leguminosas exclusivas, na forma de banco de proteína, nos trópicos brasileiros. Rev Bras Zootecn, 37: 51-67. gramíneas foi realizado em linha, ocorreu queda na concentração de 9,8 e 7,5\% para os consórcios com os capins 'Xaraés' e 'Marandu', respectivamente. Esse resultado é devido à maior porcentagem de leguminosa nesse sistema e, como o estilosantes 'Campo Grande' apresenta menor concentração de potássio (tabela IV), menores concentrações foram obtidas nessa forma de plantio.

Mesquita et al. (2004) trabalhando com doses de calcário, fósforo e gesso na $B$. decumbens consorciada com o estilosantes Mineirão, verificaram aumentos nas concentrações de cálcio, potássio e enxofre, resultando em melhoria no seu estado nutricional, o que pode ter contribuído para aumentar a porcentagem da leguminosa na pastagem.

\section{CONCLUSÕES}

A consorciação entre gramínea e leguminosa influencia no estado nutricional das forrageiras, por trazer melhoria na concentração dos nutrientes. No geral, o método de plantio em linha proporcionou melhores concentrações de nutrientes.

Cantarutti, R.B. e Boddey, R.M. 1997. Transferência de nitrogênio das leguminosas para as gramíneas. Em: Simpósio Internacional sobre Produção Animal em Pastejo, 1. Anais... DZO. Viçosa. pp. 431-445.

Carvalho, F.G.; Burity, H.A.; Silva, V.N.; Silva, L.E.S.F. e Silva, A.J.N. 2006. Produção de matéria seca e concentração de macronutrientes em Brachiaria decumbens sob diferentes sistemas de manejo na zona da mata de Pernambuco. Pesqui Agropecu Trop, 36: 101-106.

Costa, K.A.P.; Faquin, V.; Oliveira, I.P.; Araújo, J.L. e Rodrigues, R.B. 2008. Doses e fontes de nitrogênio em pastagem de capim 'Marandu': II Nutrição nitrogenada da planta. Rev Bras Ciênc Solo, 32: 1601-1607.

Costa, K.A.P.; Oliveira, I.P.; Faquin, V.; Silva, G.P. e Severiano, E.C. 2009a. Produção de massa

Archivos de zootecnia vol. 62, núm. 240, p. 522. 


\section{NUTRIENTES EM ESTILOSANTES CAMPO GRANDE EM VARIOS MÉTODOS DE PLANTIO}

seca e nutrição nitrogenada de cultivares de Brachiaria brizantha (A. Rich) Stapf sob doses de nitrogênio. Ciênc Agrotec, 33: 1578-1585.

Costa, K.A.P.; Faquin, V.; Oliveira, I.P.; Severiano, E.C.; Simon, G. A. e Carrijo, M.S. 2009b. Extração de nutrientes do capim 'Marandu' sob doses e fontes de nitrogênio. Rev Bras Saúde Prod Anim, 10: 801-812.

Costa, K.A.P.; Oliveira I.P.; Severiano, E.C.; Sampaio, F.M.T.; Carrijo, M.S. e Rodrigues, C.R. 2010. Extração de nutrientes pela fitomassa de cultivares de Brachiaria brizantha sob doses de nitrogênio. Ciênc Anim Bras, 11: 307-314.

Ferreira, D.F. 2000. Análises estatísticas por meio do Sisvar para Windows versão 4.0. In: Reunião Anual da Região Brasileira da Sociedade Internacional de Biometria. São Carlos-SP. UFSCar. pp. 255-258.

Malavolta, E. 1992. ABC da análise de solos e folhas. Agronômica Ceres. São Paulo. 124 pp.

Malavolta, E.; Liem, T.H. e Primavesi, A.C. 1986. Exigências nutricionais das plantas forrageiras. In: Calagem e adubação de pastagens. Anais... Associação Brasileira da Potassa e do Fosfato. Piracicaba. pp. 31-76.

Malavolta, E.; Vitti, G.C. e Oliveira, S.A. 1997. Avaliação do estado nutricional das plantas: princípios e aplicações. Associação Brasileira da Potassa e do Fosfato. 2. ${ }^{\text {a }}$ ed. Piracicaba. 319 pp.

Marschner, H. 1995. Mineral nutrition of higher plants. 2. ${ }^{a}$ ed. Academic. New York. 874 pp.

Mcdowell, L.R. 1999. Minerais para ruminantes sob pastejo em regiões tropicais, enfatizando o Brasil. 3. ${ }^{\mathrm{a}}$ ed. University of Florida. 89 pp.

Mesquita, E.E.; Fonseca, D.M.; Pinto, J.C.; Nascimento Junior, D.; Pereira, O.G.; Venegas, V.H.A. e Moreira, L.M. 2004. Estabelecimento de pastagem consorciada com aplicação de calcário, fósforo e gesso. Ciênc Agrotec, 28: 428-436.

Miranda, C.H.B.; Fernandes, C.D. and Cadish, G. 1999. Quantifying the nitrogen fixed by Stylo- santhes. Pasturas Tropicales, 21: 64-69.

Moreira, J.F.M.; Costa, K.A.P.; Severiano, E.C.; Epifânio, P.S.; Crunivel, W.S. and Guimarães, K.C. 2013. Protein fraction and digestibility of Marandu, Xaraes and Campo Grande grasses in monocropping and intercropping systems under different sowing methods. Acta Sci Anim Sci, 35: 63-71.

Moreira, L.M.; Fonseca, D.M.; Vítor, C.M.T.; Assis, A.J.; Nascimento Júnior, D.; Ribeiro Júnior, J.I. e Obeid, J.A. 2005. Renovação de pastagem degradada de capim-gordura com a introdução de forrageiras tropicais adubadas com nitrogênio ou em consórcios. Rev Bras Zootecn, 34: 442453.

Moura, R.L.; Nascimento, M.P.S.C.B.; Rodrigues, M.M.; Oliveira, M.E. e Lopes, J.B. 2011. Razão folha/haste e composição bromatológica da rebrota de estilosantes 'Campo Grande' em cinco idades de corte. Acta Sci Anim Sci, 33: 249-254.

Oliveira, I.P.; Costa, K.A.P.; Faquin, V.; Maciel, G.A.; Neves, B.P. e Machado, E.L. 2009. Efeitos de fontes de cálcio no desenvolvimento de gramíneas solteiras e consorciadas. Ciênc Agrotec, 33: 592-598.

Ribeiro, K.G. e Pereira, O.G. 2011. Produtividade de matéria seca e composição mineral do capimtifton 85 sob diferentes doses de nitrogênio e idades de rebrotação. Ciênc Agrotec, 35: 811 816.

Souza, S.O.; Santana, J. e Shimoya, A. 2002. Comportamento de gramíneas forrageiras tropicais isoladas e em associação com leguminosas na região norte-fluminense. Ciênc Agrotec, edição especial: 1554-1561.

Werner, J.C.; Paulino, V.T. e Cantarella, H. 1996. Forrageiras. Em: Raij, B. Van; Cantarella, H.; Quaggio, J.A. e Furlani, A.M.C. (Eds.). Recomendações de adubação e calagem para o Estado de São Paulo. Instituto Agronômico. Boletim técnico, 100. Campinas. pp. 263-273. 